\title{
Enzyme activity and genetic polymorphisms in patients with type II diabetes mellitus
}

\author{
Abdullah Arpaci ${ }^{1, A-F}$, Serap Yalın ${ }^{2, C}$, Hasret Ecevit ${ }^{3, D-F}$, Ulku Comelekoglu ${ }^{4, A, E}$, Turkan Mete ${ }^{5, A, B}$ \\ ${ }^{1}$ Department of Biochemistry, Medical Faculty, Hatay Mustafa Kemal University, Turkey \\ 2 Department of Biochemistry, Pharmacy Faculty, Mersin University, Turkey \\ ${ }^{3}$ Department of Medical Biology, Medical Faculty, Hatay Mustafa Kemal University, Turkey \\ ${ }^{4}$ Department of Biophysics, Medical Faculty, Mersin University, Turkey \\ ${ }^{5}$ Department of Gastroenterology, Samsun Training and Research Hospital, Turkey \\ A - research concept and design; B - collection and/or assembly of data; C - data analysis and interpretation; \\ $D$ - writing the article; $E$ - critical revision of the article; $F$ - final approval of the article
}

\section{Address for correspondence \\ Abdullah Arpaci \\ E-mail: arpaci57@gmail.com}

\section{Funding sources}

This study was supported with a grant from Scientific Research Projects Commission of Adıyaman University, Turkey (grant No. TIPFBAP 2010/0001).

\section{Conflict of interest}

None declared

Received on March 18, 2020

Reviewed on May 19, 2020

Accepted on July 14,2020

Published online on September 14, 2020
Cite as

Arpaci A, Yalın S, Ecevit H, Comelekoglu U, Mete T. Enzyme activity and genetic polymorphisms in patients with type II diabetes mellitus. Adv Clin Exp Med. 2020;29(9):1057-1063. doi:10.17219/acem/125397

DOI

10.17219/acem/125397

\section{Copyright}

Copyright by Author(s)

This is an article distributed under the terms of the

Creative Commons Attribution 3.0 Unported (CC BY 3.0)

(https://creativecommons.org/licenses/by/3.0/)

\section{Abstract}

Background. Diabetes mellitus (DM) has become more and more common and has a high morbidity and mortality rate worldwide. It is a multifactorial chronic disease affected by both genetic and environmental factors.

Objectives. To evaluate the association between antioxidant enzyme activities and their genetic variations and the level of malondialdehyde (MDA) in type II diabetes patients living in the Adıyaman province in the southeast part of Turkey.

Material and methods. One hundred patients diagnosed with type II DM (T2DM) and 100 healthy controls were included in the study. Malondialdehyde levels and antioxidant enzyme activities were measured spectrophometrically. DNA isolation was performed and genotyping was carried out using polymerase chain reaction-restriction fragment length polymorphism (PCR-RFLP).

Results. Our results revealed no significant differences in genotype distributions and allele frequencies of all polymorphisms between groups ( $p>0.05$ ). Significantly elevated MDA levels and a significant reduction in catalase (CAT) and paraoxonase (PON) enzyme activities were observed in patients compared to the control group in terms of study groups and genetic variations $(p<0.05)$. Moreover, CAT activity was reduced in TT genotype in terms of CAT -262 C/T polymorphism in patients $(p<0.05)$. Paraoxonase activity was observed to be lower in MM genotype in both groups $(p<0.05)$.

Conclusions. CAT -262 C/T polymorphism may be one of the factors that lead to severe clinical situation in DM. Our results suggest that TT genotype may be more prone to lipid peroxidation.

Key words: diabetes mellitus, oxidative stress, cat, malondialdehyde, paraoxonase 


\section{Introduction}

Diabetes mellitus (DM) has become more and more common and has a high morbidity and mortality rate worldwide. It is a multifactorial chronic disease affected by both genetic and environmental factors. ${ }^{1,2}$ Type II DM (T2DM) account for $90 \%$ of the DM cases. The reduction of insulin secretion or development of insulin resistance results in the impairment of macromolecule metabolisms, such as proteins, carbohydrates and lipids. ${ }^{3,4}$ The pharmaceutical development of insulin revolutionized the treatment of DM, but T2DM is still the most common disease globally with chronic complications. ${ }^{4,5}$

The complications of DM can be expressed with 4 major mechanisms, including the production of reactive oxygen species (ROS), which is triggered by hyperglycemia, polyol pathway, the formation of advanced glycosylation end products (AGE), activation of protein kinase $C$, and hexamine pathway. ${ }^{6}$ Several factors, such as environmental factors, genetic risk factors, obesity, and oxidative stress, may all be associated with the development of T2DM. The oxidant/antioxidant balance in the organism shifts towards oxidation with a potential which results in the development of organopathies, such as cardiomyopathies, neuropathies and retinopathies. ${ }^{6,7}$ The excessive level of free radicals and ROS may result in several cellular injuries. In such cases, the antioxidant system may be insufficient to defend the cell against free-radical structures. The major components of the antioxidant system are enzymatic antioxidants, such as superoxide dismutase (SOD), catalase $(\mathrm{CAT})$, paraoxonase 1 (PON1), and glutathione peroxidase (GPx). ${ }^{7,8}$

Our study aims to examine the association between CAT -262 cysteine $(\mathrm{C}) /$ threonine $(\mathrm{T})$ and PON1 55 leucine $(\mathrm{L}) /$ methionine $(\mathrm{M})$ genetic polymorphisms, CAT and PON1 antioxidant enzyme activities, and the level of oxidative damage marker malondialdehyde (MDA) in T2DM.

\section{Material and methods}

\section{Sample collection}

This study included a total of 200 individuals consisting of 100 healthy controls without any disorders (including DM) in their medical histories and 100 patients diagnosed with T2DM who were admitted to the Internal Clinic at Adryaman University Training and Research Hospital, Turkey. The confirmation by Adıyaman University Ethic Committee (approval No. 2011/02-1) and a written consent from each subject have been provided after participants were properly informed. All experiments were performed according to the Declaration of Helsinki.

\section{Biochemical analyzes}

Fasting venous blood samples were collected into EDTA tubes and centrifuged at $3000 \mathrm{rpm}$ for $10 \mathrm{~min}$. After centrifugation, the plasma portion was separated and stored at $-20^{\circ} \mathrm{C}$ until the analyses were performed. The enzymatic activities of CAT and PON1, and the level of MDA, the end product of lipid peroxidation, as an indicator of oxidative stress, were measured. Malondialdehyde forms a pink colored complex as a result of its incubation with thiobarbituric acid at a $\mathrm{pH}$ of 3.5 and $95^{\circ} \mathrm{C}$ in aerobic conditions. Based on this principle, the amount of MDA was determined with spectrophotometric measurement of this complex at $532 \mathrm{~nm} .{ }^{9}$ The CAT enzyme activity was determined using spectrophotometric measurement of the substrate molecule hydrogen peroxide $\left(\mathrm{H}_{2} \mathrm{O}_{2}\right)$ absorbance; it decreased over time as a result of its interaction with catalase at $240 \mathrm{~nm} .{ }^{10}$

The PON1 activity was determined in alignment with the technique developed by Eckerson et al., which is based on monitoring the production of p-nitrophenol by the enzymatic hydrolysis of PON1 at $412 \mathrm{~nm}$. A $100 \mathrm{mM}$ Tris- $\mathrm{HCl}$ at $\mathrm{pH} 8$, containing $2 \mathrm{mM} \mathrm{CaCl}_{2}$ and $4 \mathrm{mM}$ paraoxon was used as a buffer to measure its activity. ${ }^{11}$

\section{Molecular analyses}

For the molecular analysis, leukocytes were separated from whole blood samples and DNA isolation was performed according to the method described by Poncz et al. ${ }^{12}$ Genotype determination was carried out using the polymerase chain reaction-restriction fragment length polymorphism (PCR-RFLP) technique.

The most commonly studied PON1 55 L/M polymorphism was determined using the PCR-RFLP method. The PCR amplification samples were digested with Nla III restriction endonuclease. Digestion products were separated on $2 \%$ agarose gel and visualized with ultraviolet light after ethidium bromide staining. Alleles of leucine and methionine for the PON1 55 position were assigned based on the presence of a $172 \mathrm{bp}$ (undigested) fragment and $106 \mathrm{bp}$ and $66 \mathrm{bp}$ (digested) fragments, respectively. ${ }^{13,14}$ CAT $-262 \mathrm{C} / \mathrm{T}$ polymorphism was similarly determined using PCR-RFLP method. The PCR amplification samples were digested with SmaI restriction endonuclease. Then, the digested products were separated on an agarose gel and visualized with ultraviolet light after ethidium bromide staining. The alleles of CAT $-262 \mathrm{C} / \mathrm{T}$ polymorphism, threonine and cysteine were assigned based on the presence of a 340 bp (undigested) fragment and 185 bp and $155 \mathrm{bp}$ (digested) fragments, respectively. ${ }^{15}$

The statistical analyses were performed using MedCalc v. 12.3 software (MedCalc, Ostend, Belgium). The Shapiro-Wilk test was used to determine whether all parameters were normally distributed. Abnormally distributed data are presented as median (min-max) and 
mean \pm standard deviation (SD), and group comparisons were conducted using the Mann-Whitney U test. The $\chi^{2}$ and Fisher's tests were used to evaluate the differences between the groups in terms of the genotype distribution and allele frequencies. Statistical significance for all analyses was set at a p-value $<0.05$.

\section{Results}

\section{Biochemical analysis}

In the current study, descriptive statistic data of biochemical analyses of study groups were given in Table 1 . Malondialdehyde levels were found to be significantly higher in the diabetic group compared to the control ( $\mathrm{p}<0.0001)$. A significant reduction in plasma CAT and PON1 enzyme activities was observed in the diabetic group ( $\mathrm{p}<0.0001)$. Descriptive statistic data of biochemical analyses were displayed in Table 2.

\section{Molecular analysis}

There was no statistically significant difference between the diabetic and control groups with respect to genetic distribution and allele frequencies of CAT $-262 \mathrm{C} / \mathrm{T}$ and PON1 $55 \mathrm{~L} / \mathrm{M}$ polymorphisms ( $\mathrm{p}>0.05$ ). The genotype distributions and allele frequencies of the CAT $-262 \mathrm{C} / \mathrm{T}$ and PON1 $55 \mathrm{~L} / \mathrm{M}$ polymorphisms between diabetic and control groups were displayed in Table 3.

In PON1 $55 \mathrm{~L} / \mathrm{M}$ polymorphism, the activity of the PON1 enzyme was lower for carriers of the MM allele, both in diabetic and control group compared to LL and LM genotypes $(\mathrm{p}=0.0001)($ Table $4 \mathrm{~A})$. In all genotypes, the MDA
Table 1. Descriptive statistic data of biochemical analyses

\begin{tabular}{|l|c|c|c|}
\multicolumn{1}{|c|}{ Parameter } & $\begin{array}{c}\text { T2DM group } \\
\text { mean } \pm \text { SD }\end{array}$ & $\begin{array}{c}\text { Control group } \\
\text { mean } \pm \text { SD }\end{array}$ & p-value \\
\hline HbA1c [\%] & $8.92 \pm 2.56$ & - & - \\
\hline Insulin $[\mathrm{mLU} / \mathrm{L}]$ & $10.65 \pm 15.16$ & - & - \\
\hline FBG $[\mathrm{mmol} / \mathrm{L}]$ & $10.95 \pm 5.62$ & $5.15 \pm 0.40$ & $<0.0001^{* * *}$ \\
\hline $\mathrm{CHO}[\mathrm{mg} / \mathrm{dL}]$ & $208.6 \pm 45.95$ & $180.2 \pm 41.79$ & $0.0003^{* * *}$ \\
\hline $\mathrm{TG}[\mathrm{mg} / \mathrm{dL}]$ & $185.1 \pm 108.8$ & $115.9 \pm 63.25$ & $<0.0001^{* * *}$ \\
\hline $\mathrm{HDL}-\mathrm{CHO}[\mathrm{mg} / \mathrm{dL}]$ & $40.36 \pm 9.7$ & $42.59 \pm 10.46$ & 0.236 \\
\hline LDL-CHO $[\mathrm{ng} / \mathrm{dL}]$ & $131.5 \pm 34.92$ & $113.9 \pm 33.75$ & $0.0038^{* *}$ \\
\hline Age & $56.75 \pm 10.86$ & $36.65 \pm 14.67$ & $<0.0001^{* * *}$ \\
\hline HOMA-IR & $5.91 \pm 11.55$ & - & - \\
\hline HOMA- $\beta$ & $36.14 \pm 33.82$ & - & - \\
\hline
\end{tabular}

Mann-Whitney $U$ test; ${ }^{*} p<0.05 ;{ }^{* *} p<0.01 ; * * * 00.001 ;$ T2DM - type 2 diabetes mellitus; HbA1c - glycated hemoglobin; FBG - fasting blood glucose; $\mathrm{CHO}$ - cholesterol; TG - triglycerides; $\mathrm{HDL}-\mathrm{CHO}$ - high-density lipoprotein cholesterol; LDL-CHO - low-density lipoprotein cholesterol; HOMA-IR - homeostatic model assessment for insulin resistance; HOMA- $\beta$ - homeostatic model assessment for $\beta$-cell function.

Table 2. Descriptive statistic data of biochemical analyses

\begin{tabular}{|l|c|c|c|}
\multirow{2}{*}{ Variable } & $\begin{array}{c}\text { T2DM group } \\
(\mathrm{n}=100)\end{array}$ & $\begin{array}{c}\text { Control group } \\
(\mathrm{n}=100)\end{array}$ & \multirow{2}{*}{ p-value } \\
\cline { 2 - 3 } & $\begin{array}{c}\text { median } \\
(\min -\max )\end{array}$ & $\begin{array}{c}\text { median } \\
(\min -\max )\end{array}$ & \\
\hline MDA [nmol/L] & $\begin{array}{c}13.56 \\
(4.25-43.31)\end{array}$ & $\begin{array}{c}7.06 \\
(1.36-10.76)\end{array}$ & $0.0001^{* * *}$ \\
\hline CAT [U/L] & 19.50 & 47.16 & \multirow{2}{*}{$0.0001^{* * *}$} \\
\hline PON [U/L] & $(6.03-54.91)$ & $(9.87-89.25)$ & $0.0001^{* * *}$ \\
\hline
\end{tabular}

Mann-Whitney U test; ${ }^{*} \mathrm{p}<0.05 ;{ }^{* *} \mathrm{p}<0.01$; ${ }^{* * *} \mathrm{p}<0.001$; T2DM - type 2 diabetes mellitus; MDA - malondialdehyde; CAT - catalase; PON - paraoxonase.

Table 3. The genotype distributions and allele frequencies of the CAT $-262 \mathrm{C} / \mathrm{T}$ and PON55 L/M polymorphisms between diabetic patients and control group

\begin{tabular}{|c|c|c|c|c|c|c|c|}
\hline \multirow{2}{*}{ Genotype } & \multicolumn{2}{|c|}{ Control group $(n=100)$} & \multicolumn{2}{|c|}{ T2DM group $(n=100)$} & \multirow{2}{*}{$\frac{\mathrm{x}^{2} \text { test }}{\mathrm{p} \text {-value }}$} & \multirow{2}{*}{$\frac{\text { Interval }}{\text { OR }(95 \% \mathrm{Cl})}$} & \multirow{2}{*}{$\frac{\text { OR }}{p \text {-value }}$} \\
\hline & $\mathrm{n}$ & $\%$ & $\mathrm{n}$ & $\%$ & & & \\
\hline \multicolumn{8}{|c|}{ CAT } \\
\hline $\mathrm{TT}$ & 35 & 35 & 29 & 29 & \multirow{3}{*}{0.522} & 1 & reference \\
\hline CT & 52 & 52 & 60 & 60 & & $1.393(0.75-2.58)$ & 0.292 \\
\hline CC & 13 & 13 & 11 & 11 & & $1.021(0.39-2.62)$ & 0.965 \\
\hline $\begin{array}{l}\text { Allele frequency } \\
\text { T } \\
\mathrm{C}\end{array}$ & $\begin{array}{l}122 \\
78\end{array}$ & $\begin{array}{l}61 \\
39\end{array}$ & $\begin{array}{l}118 \\
82\end{array}$ & $\begin{array}{l}59 \\
41\end{array}$ & 0.904 & $\begin{array}{c}- \\
1.087(0.73-1.62)\end{array}$ & $\begin{array}{c}- \\
0.683\end{array}$ \\
\hline \multicolumn{8}{|c|}{ PON55 } \\
\hline LL & 50 & 50 & 47 & 47 & \multirow{3}{*}{0.878} & - & - \\
\hline LM & 38 & 38 & 39 & 39 & & $1.092(0.60-1.99)$ & 0.774 \\
\hline MM & 12 & 12 & 14 & 14 & & $1.241(0.52-2.96)$ & 0.626 \\
\hline $\begin{array}{l}\text { Allele frequency } \\
L \\
M\end{array}$ & $\begin{array}{c}138 \\
62\end{array}$ & $\begin{array}{l}69 \\
31\end{array}$ & $\begin{array}{c}133 \\
67\end{array}$ & $\begin{array}{l}66.5 \\
33.5\end{array}$ & 0.669 & $\begin{array}{c}- \\
1.212(0.74-1.71)\end{array}$ & $\begin{array}{c}- \\
0.593\end{array}$ \\
\hline
\end{tabular}

$X^{2}$ test; ${ }^{*} \mathrm{p}<0.05 ;{ }^{* *} \mathrm{p}<0.01 ;{ }^{* * *} \mathrm{p}<0.001 ; \mathrm{T} 2 \mathrm{DM}$ - type 2 diabetes mellitus; CAT - catalase; OR - odds ratio; $95 \% \mathrm{Cl}$ - 95\% confidence interval. 
Table 4. Genotype comparison in terms of PON 55 L/M polymorphism (A) and CAT -262 C/T polymorphism (B)

\begin{tabular}{|c|c|c|c|c|c|c|}
\hline \multirow{3}{*}{ Parameters } & \multicolumn{3}{|c|}{ A. PON 55 L/M polymorphism } & \multicolumn{3}{|c|}{ B. CAT -262 C/T polymorphism } \\
\hline & \multirow{2}{*}{ genotype } & $\begin{array}{l}\text { T2DM group } \\
(\mathrm{n}=100)\end{array}$ & $\begin{array}{l}\text { control group } \\
(n=100)\end{array}$ & \multirow{2}{*}{ genotype } & $\begin{array}{l}\text { T2DM group } \\
(\mathrm{n}=100)\end{array}$ & $\begin{array}{l}\text { control group } \\
(n=100)\end{array}$ \\
\hline & & $p$-value & $\mathrm{p}$-value & & $p$-value & $p$-value \\
\hline \multirow{3}{*}{ MDA [nmol/L] } & LL-LM & 0.122 & 0.736 & $\mathrm{CC}-\mathrm{CT}$ & 0.962 & 0.780 \\
\hline & LL-MM & 0.204 & 0.428 & CC-TT & 0.743 & 0.702 \\
\hline & LM-MM & 0.944 & 0.407 & CT-TT & 0.602 & 0.931 \\
\hline \multirow{3}{*}{ CAT [U/L] } & LL-LM & 0.609 & 0.950 & $\mathrm{CC}-\mathrm{CT}$ & 0.259 & 0.857 \\
\hline & LL-MM & 0.237 & 1.000 & CC-TT & 0.492 & 0.618 \\
\hline & LM-MM & 0.408 & 1.000 & CT-TT & $0.017^{*}$ & 0.348 \\
\hline \multirow{3}{*}{ PON [U/L] } & LL-LM & 0.184 & 0.646 & $\mathrm{CC}-\mathrm{CT}$ & 0.195 & 0.522 \\
\hline & LL-MM & $0.0001^{* * *}$ & $0.0001^{* * *}$ & CC-TT & 0.116 & 0.359 \\
\hline & LM-MM & $0.0001^{* * *}$ & $0.0001^{* * *}$ & CT-TT & 0.546 & 0.634 \\
\hline
\end{tabular}

Mann-Whitney U test; ${ }^{*} \mathrm{p}<0.05 ;{ }^{* *} \mathrm{p}<0.01 ;{ }^{* *} \mathrm{p}<0.001 ; \mathrm{T} 2 \mathrm{DM}$ - type 2 diabetes mellitus; MDA - malondialdehyde; CAT - catalase; PON - paraoxonase.

level was observed to be significantly higher $(\mathrm{p}=0.0001$ for LL and LM genotypes, $\mathrm{p}=0.002$ for MM genotype, respectively), while CAT ( $\mathrm{p}=0.0001$ for LL and LM genotypes, $\mathrm{p}=0.001$ for MM genotype, respectively) and PON1 ( $\mathrm{p}=0.0001$ for all genotypes) enzyme activities were observed to be significantly lower in patient group compared to control (Fig. 1).

No significant differences were observed regarding CAT $-262 \mathrm{C} / \mathrm{T}$ polymorphism between genotypes in the control group ( $p>0.05$ ). However, CAT activity was seen to be significantly lower in TT genotype compared to CT genotype in the T2DM group ( $\mathrm{p}=0.017)$ (Table 4B). Moreover, in all genotypes, MDA level was observed to be significantly higher ( $\mathrm{p}=0.001$ for CC genotype, $\mathrm{p}=0.0001$ for $\mathrm{CT}$ and TT genotypes, respectively), whereas CAT ( $\mathrm{p}=0.004$ for $\mathrm{CC}$ genotype, $\mathrm{p}=0.0001$ for $\mathrm{CT}$ and TT genotypes, respectively) and PON1 ( $p=0.001$ for CC genotype, $p=0.0001$ for $\mathrm{CT}$ and TT genotypes, respectively) enzyme activities were observed to be significantly lower in the T2DM compared to the control group (Fig. 2).

\section{Discussion}

Diabetes mellitus has a very high incidence of $10.9 \%$ in countries of the Middle East and North Africa, including Turkey as well. The incidence in Turkey is reported to be $14.85 \%$ and it constitutes a major health problem. ${ }^{16}$ According to the report by International Diabetes Federation (IDF) from 2015, there are 415 million diabetic patients in the world and it is estimated that this figure will reach 642 million in $2040 .{ }^{17}$ Diabetes is an oxidative stress state, in which free radicals are increased and/ or antioxidant mechanisms are inhibited. The production of free radicals increases as a result of protein glycation and glucose autoxidation. ${ }^{6}$ Oxidative stress causes bodily complications such as nephropathy, cardiovascular diseases and neuropathy, all of which decrease the quality of life. ${ }^{9}$
Although the genetic predisposition is recognized in DM, the information on the specific genetic defects is limited. ${ }^{6}$ Therefore, we aimed to examine the oxidative stress state in T2DM by evaluating antioxidant enzyme activities and its association with their polymorphisms in our geographical region. There are 2 reasons why we carry out our study in the southeast region of our country. The population living in this region does not have the habit of eating a Mediterranean type diet and has of a different ethnic structure compared to some other regions of our country.

Malondialdehyde has been studied as a lipid oxidation indicator. We have found significantly high levels of MDA in diabetic patients compared to the control group, similarly to the previous studies, confirming the presence of severe oxidative stress in our patients. ${ }^{18,19}$ Likewise, the enzyme activities of CAT and PON1 were found to be significantly reduced in diabetic patients compared to the control group. Our enzymatic activity results are consistent with most recent studies. ${ }^{20,21}$ Unlike our study, Sozmen et al. and Memisogullari et al. reported increased CAT enzyme activity in diabetic patients. ${ }^{22,23}$ The impact of environmental factors (climate, air pollution, nutrition, lifestyle, etc.) and genetic background on DM development is indisputable. For example, Sozmen et al. carried out their study in a different region of Turkey in terms of eating habits (where the Mediterranean-type eating habit is preferred) and ethnicity, compared to our study (Adiyaman region). This may be the reason for the different results we have achieved regarding CAT enzyme activity. Therefore, the role of antioxidant defense mechanism in diabetic patients is controversial and requires further research, in which genetic background may be at least partly elucidated. Our study results may suggest that oxidative stress has developed in our patients and the antioxidant mechanism has become insufficient.

The issue of the effect of antioxidant enzyme polymorphisms on DM is unclear and controversial. Flekac et al. studied genetic polymorphisms of SOD and CAT 
A

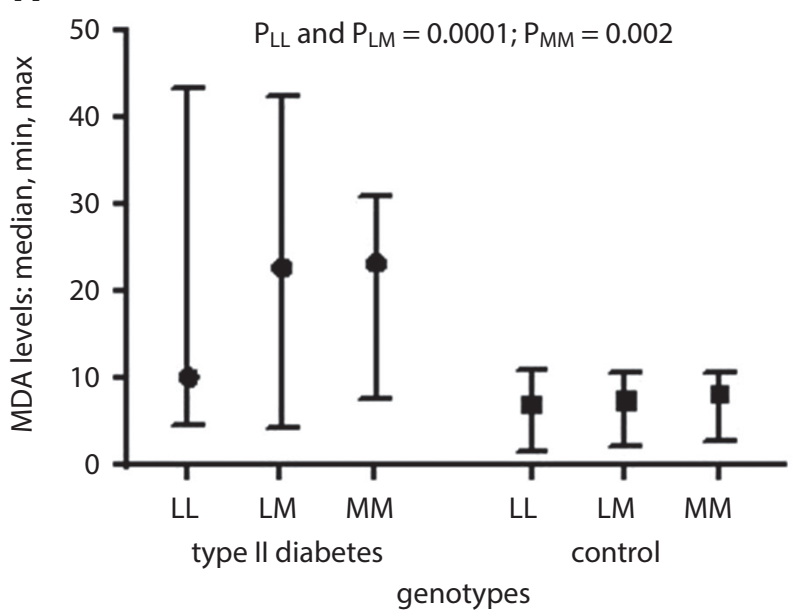

B

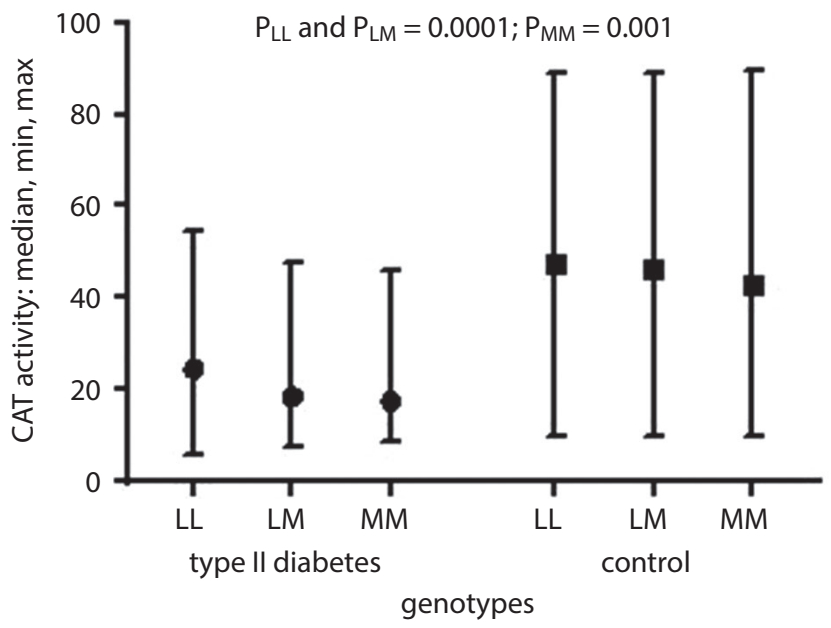

C

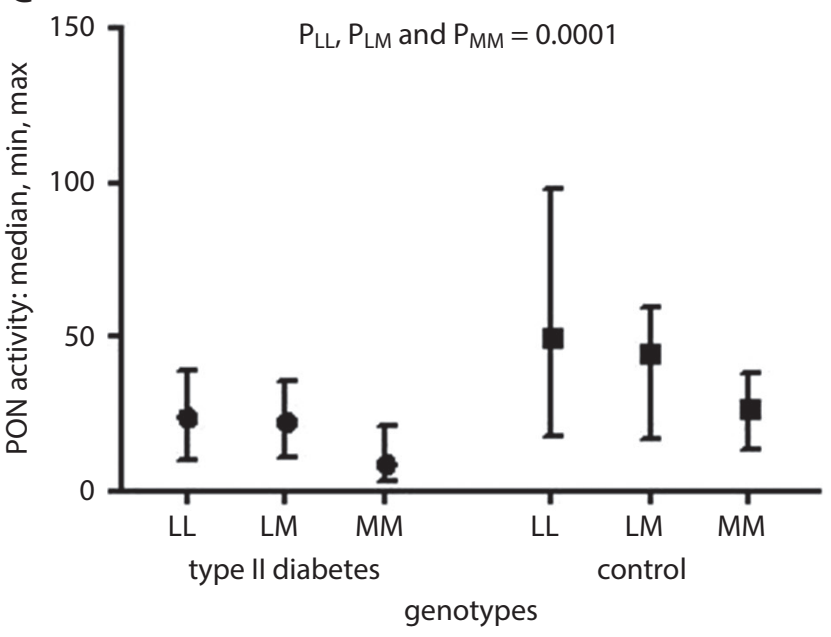

Fig. 1. PON $55 \mathrm{~L} / \mathrm{M}$ polymorphism genotype comparison in terms of MDA level (A), and CAT (B), PON (C) enzyme activities between controls (circle) and patients (square) with T2DM

in patients with $\mathrm{DM}$, concluding that the superoxide dismutase (SOD) activity was higher in the CC and AA genotypes compared to the TT and CC genotypes of SOD Ala-9Val and SOD $+35 \mathrm{~A} / \mathrm{C}$ polymorphisms, respectively
A
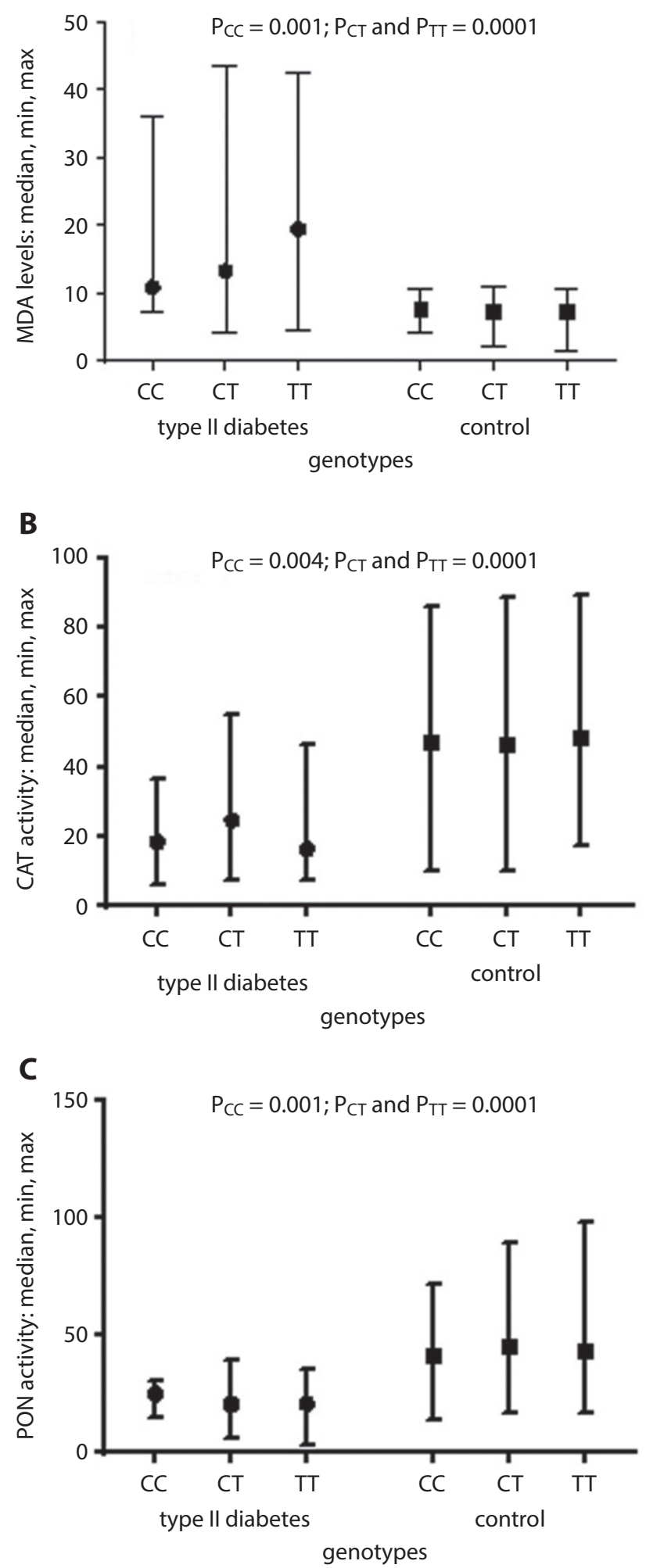

Fig. 2. CAT -262 C/T polymorphism genotype comparison in terms of MDA level (A) and CAT (B), PON (C) enzyme activities between controls (circle) and patients (square) with T2DM

$(\mathrm{p}<0.05)$. Moreover, they found significant differences regarding allele frequencies of SOD Ala-9Val polymorphism between control and diabetic groups. $\mathrm{T}$ allele expression level was observed to be significantly higher, whereas 
C allele expression was significantly lower in the diabetic group compared to the control $(\mathrm{p}<0.05)$. However, they did not observe any association with CAT polymorphism. ${ }^{24}$ Kasznicki et al. did not observe any significant change in CAT and SOD enzyme activities between T2DM patients and controls as well as any association between their polymorphisms (CAT $-262 \mathrm{C} / \mathrm{T}$ and SOD $+35 \mathrm{~A} / \mathrm{C}$ ) and activity of these polymorphisms. ${ }^{20}$ In our study, CAT activity was found to be significantly lower in TT genotype, which is in line with previous study performed by Flekac et al. compared to CT genotype in diabetic group, which suggests a significant association. CAT $-262 \mathrm{C} / \mathrm{T}$ polymorphism may be at least partly responsible for the reduction of CAT enzyme activity which mediates oxidative stress state and leads to severe clinic situation in DM (secondary effect of DM developing over time such as frequent urination, fatigue, tiredness, blurred vision, frequent infections, itching and dryness of the skin, loss of weight, micro- and macrovascular damage which reduce quality of life over time). Moreover, in all genotypes of all polymorphisms examined in our study, CAT activity was observed to be significantly lower in the diabetic group when compared to the control. Any significant difference was not observed in terms of genetic distribution and allele frequencies of CAT $-262 \mathrm{C} / \mathrm{T}$ between the diabetic and the control group. Tarnai et al. observed an elevation in the catalase enzyme activity in $\mathrm{CT}+\mathrm{TT}$ genotype of $\mathrm{C} 111 \mathrm{~T}$ polymorphism in patients with T2DM. ${ }^{25}$ Therefore, the relation between DM and polymorphisms of CAT and SOD is considered controversial because of previous studies with different results. There are studies in which the relationship between polymorphisms and enzyme activity has been shown, ${ }^{25,26}$ as well as studies in which such relationship was not found. ${ }^{27,28}$

Gupta et al. studied serum PON1 activity and its different polymorphisms in T2DM patients in an ethnic population in northwestern India. They found significant reductions in the enzyme activity compared to the control group, similarly to our findings. Moreover, PON enzyme activity was reported to be significantly lower in all genotypes of diabetic patients compared to control group in terms of both PON1 192 Q/R and PON1 55 L/M polymorphisms. In addition, the enzyme activity was found to be highest in the RR genotype, whereas it was the lowest in the QQ genotype in both diabetic patients and controls. ${ }^{29}$ Gupta et al. observed a higher enzyme activity in LL genotype compared to the LM genotype in the control group. However, they did not find a significant difference in the diabetic group. ${ }^{29}$ Altuner et al. studied PON1 polymorphisms in the middle geographical region of Turkey (in Ankara). They reported reduced activities of PON1 in QQ and QR genotypes compared to RR genotype in terms of PON1 192 $\mathrm{Q} / \mathrm{R}$ polymorphism both in control and diabetic groups. Similarly, they reported higher PON1 enzyme activity in LL genotype compared to MM in terms of PON1 $55 \mathrm{~L} / \mathrm{M}$ polymorphism in both diabetic and control groups, which is in line with our results. They did not report any significant difference between the control and diabetic groups in terms of genotype distributions and allele frequencies. ${ }^{30}$

In our study, PON1 enzyme activity was observed to be lower in MM genotype compared to LL genotype in terms of PON1 $55 \mathrm{~L} / \mathrm{M}$ polymorphism in both the T2DM and the control groups, which was in line with a previous study carried out in Turkey by Altuner et al. ${ }^{30}$ In addition, we observed significantly lower PON1 enzyme activity in all genotypes in the T2DM group compared to the controls, which was in line a study performed by Gupta et al., whereas Altuner et al. did not report any significant difference between the groups in terms of genotype distributions and allele frequencies. ${ }^{29,30}$ As can be seen, there are similarities and differences between our study results and previous studies. This can be explained by the fact that different studies were performed in regions with different environmental conditions (climate, air pollution, nutrition, lifestyle, etc.) and in study populations with different genetic backgrounds and ethnicities. However, when the current studies are evaluated, PON1 $55 \mathrm{~L} / \mathrm{M}$ polymorphism does not seem to have a significant effect on the development of T2DM.

\section{Conclusions}

In this study, we concluded that there was a significant state of oxidative stress in diabetic patients. In addition, CAT enzyme activity was observed to be lower in TT genotype within the diabetic group, which suggests an association between CAT $-262 \mathrm{C} / \mathrm{T}$ polymorphism and T2DM. Therefore, genetic testing in T2DM may be useful in the future to determine the relationship between genetic and environmental factors in development of the disease and its complications as well as the genetic predisposition, which requires further studies to confirm.

\section{ORCID iDs}

Abdullah Arpaci (1) https://orcid.org/0000-0002-6077-8258

Serap Yalın (10) https://orcid.org/0000-0002-1286-2172

Hasret Ecevit (1) https://orcid.org/0000-0002-4444-475X

Ulku Comelekoglu (1) https://orcid.org/0000-0001-8060-6333

Turkan Mete (1) https://orcid.org/0000-0002-4159-1965

\section{References}

1. Gray SP, Jandeleit-Dahm K. The pathobiology of diabetic vascular complications: Cardiovascular and kidney disease. J Mol Med (Berl). 2014;92(5):441-452.

2. Banerjee $M$, Vats P. Reactive metabolites and antioxidant gene polymorphisms in Type 2 diabetes mellitus. Redox Biol. 2014;2:170-177.

3. Ahmed FN, Naqvi FN, Shafiq F. Lipid peroxidation and serum antioxidantenzymes in patients with type 2 diabetes mellitus. AnnNYAcad Sci. 2006;1084:481-489.

4. International Diabetes Federation. International Diabetes Federation Diabetes Atlas. $8^{\text {th }}$ ed. International Diabetes Federation; 2017. https://www.idf.org/e-library/epidemiology-research/diabetes-atlas/ 134-idf-diabetes-atlas-8th-edition.html. Chapter 1:18.

5. Bednarek E, Sitkowski J, Bocian W, et al. Structure and pharmaceutical formulation development of a new long-acting recombinant human insulin analog studied by NMR and MS. J Pharm Biomed Anal. 2017;135:126-132. 
6. Tabatabaei-Malazy O, Khodaeian M, Bitarafan F, Larijani B, Amoli MM. Polymorphisms of antioxidant genes as a target for diabetes management. Int J Mol Cell Med. 2017;6(3):135-147.

7. Van Dam PS, Van Asbeck BS, Erkelens DW, Marx JJ, Gispen WH, Bravenboer $B$. The role of oxidative stress in neuropathy and other diabetic complications. Diabetes Metab Rev. 1995;11(3):181-192.

8. Bullon P, Newman HN, Battino M. Obesity, diabetes mellitus, atherosclerosis and chronic periodontitis: A shared pathology via oxidative stress and mitochondrial dysfunction? Periodontol 2000. 2014; 64(1):139-153.

9. Yagi K. Simple procedure for specific assay of lipid hydroperoxides in serum or plasma. Methods Mol Biol. 1998;108:107-110.

10. Aebi H. Catalase in vitro. Methods Enzymol. 1984;105:121-126.

11. Eckerson HW, Wyte CM, La Du BN. The human serum paraoxonase/ arylesterase polymorphism. Am J Hum Genet. 1983;35(6):1126-1138.

12. Poncz M, Solowiejczyk D, Harpel B, Mory Y, Schwartz E, Surrey S. Construction of human gene libraries from small amounts of peripheral blood: Analysis of beta-like globin genes. Hemoglobin. 1982;6(1): 27-36.

13. Lakshmy R, Ahmad D, Abraham RA, et al. Paraoxonase gene Q192R \& L55M polymorphisms in Indians with acute myocardial infarction \& association with oxidized low density lipoprotein. Indian J Med Res. 2010;131:522-529.

14. HumbertR, AdlerDA, DistecheCM, HassettC,OmiecinskiCJ,Furlong CE. The molecular basis of the human serum paraoxonase activity polymorphism. Nat Genet. 1993;3(1):73-76.

15. Goulas A, Fidani L, Kotsis A, et al. An association study of a functional catalase gene polymorphism, -262C-->T, and patients with Alzheimer's disease. Neurosci Lett. 2002;330(2):210-213.

16. Kharroubi AT, Darwish HM. Diabetes mellitus: The epidemic of the century. World J Diabetes. 2015;6(6):850-867.

17. Ogurtsova $K$, da Rocha Fernandes JD, Huang Y, et al. IDF Diabetes Atlas: Global estimates for the prevalence of diabetes for 2015 and 2040. Diabetes Res Clin Pract. 2017;128:40-50.

18. Banerjee J, Mishra N, Damle G, et al. Beyond LDL-c: The importance of serum oxidized LDL in predicting risk for type 2 diabetes in the middle-aged Asian Indians. Diabetes Metab Syndr. 2019;13(1):206-213.

19. Ghazizadeh $Z$, Khaloo $P$, Alemi $H$, et al. Definition of an oxidative stress status by combined assessment of malondialdehyde and oxidized-LDL: A study in patients with type 2 diabetes and control. Meta Gene. 2019;19:91-97.
20. Kasznicki J, Sliwinska A, Kosmalski M, et al. Genetic polymorphisms (Pro197Leu of Gpx1, +35A/C of SOD1,-262C/T of CAT), the level of antioxidant proteins (GPx1, SOD1, CAT) and the risk of distal symmetric polyneuropathy in Polish patients with type 2 diabetes mellitus. Adv Med Sci. 2016;61(1):123-129.

21. Tartan Z, Orhan G, Kasikcioglu H, et al. The role of paraoxonase (PON) enzyme in the extent and severity of the coronary artery disease in type-2 diabetic patients. Heart Vessels. 2007;22(3):158-164.

22. Sozmen EY, Sozmen B, Delen Y, Onat T. Catalase/superoxide dismutase (SOD) and catalase/paraoxonase (PON) ratios may implicate poor glycemic control. Arch Med Res. 2001;32(4):283-287.

23. Memisogullari R, Taysi S, Bakan E, Capoglu I. Antioxidant status and lipid peroxidation in type II diabetes mellitus. Cell Biochem Funct. 2003;21(3):291-296.

24. Flekac M, Skrha J, Hilgertova J, Lacinova Z, Jarolimkova M. Gene polymorphisms of superoxide dismutases and catalase in diabetes mellitus. BMC Med Genet. 2008;9:30.

25. Tarnai I, Csordas M, Sukei E, Shemirani AH, Káplár M, Góth L. Effect of C111T polymorphism in exon 9 of the catalase gene on blood catalase activity in different types of diabetes mellitus. Free Radic Res. 2007;41(7):806-811.

26. Houldsworth A, Hodgkinson A, Demaine A, et al. Catalase polymorphism may influence the pathogenesis of diabetes mellitus. J Endocrinol Diabetes. 2016;3(6):1-7.

27. dos Santos KG, Canani LH, Gross JL, et al. The catalase - $262 \mathrm{C} / \mathrm{T}$ promoter polymorphism and diabetic complications in Caucasians with type 2 diabetes. Dis Markers. 2006;22(5-6):355-359.

28. Pask R, Cooper JD, Walker NM, et al. No evidence for a major effect of two common polymorphisms of the catalase gene in type 1 diabetes susceptibility. Diabetes Metab Res Rev. 2006;22(5):356-360.

29. Gupta N, Binukumar BK, Singh S, et al. Serum paraoxonase-1 (PON1) activities (PONase/AREase) and polymorphisms in patients with type 2 diabetes mellitus in a North-West Indian population. Gene. 2011;487(1):88-95.

30. Altuner D, Ates I, Suzen SH, Koc GV, Aral Y, Karakaya A. The relationship of PON1 QR 192 and LM 55 polymorphisms with serum paraoxonase activities of Turkish diabetic patients. Toxicol Ind Health. 2011;27(10):873-878 